\title{
Delivery mode for the extremely premature fetus: a statement of the prematurity working group of the World Association of Perinatal Medicine
}

\author{
Daniel W. Skupski ${ }^{1, *}$, Anne Greenough ${ }^{2}$, \\ Stephen M. Donn ${ }^{3}$, Birgit Arabin ${ }^{4}$, Eduardo \\ Bancalari ${ }^{5}$ and Radu Vladareanu ${ }^{6}$ \\ 1 Division of Obstetrics and Gynecology, Weill Cornell \\ Medical College, New York, NY, USA \\ 2 Division of Asthma, Allergy and Lung Biology, King's \\ College London School of Medicine, Newborn Unit, \\ London, UK \\ ${ }^{3}$ Division of Neonatal-Perinatal Medicine, University of \\ Michigan, Ann Arbor, MI, USA \\ ${ }^{4}$ Division of Obstetrics and Gynecology, University \\ Hospital of Marburg, Germany \\ ${ }^{5}$ Division of Neonatology, University of Miami Miller \\ School of Medicine, Miami, FL, USA \\ ${ }^{6}$ Division of Obstetrics and Gynecology, Elias University \\ Hospital, Carol Davila University of Medicine, \\ Bucharest, Romania
}

\begin{abstract}
Recent retrospective publications have suggested that cesarean delivery may be beneficial for the extremely premature fetus. This article displays the available evidence and discusses this issue, including many aspects such as the difficulty in deciding when delivery is imminent, the negative impact on maternal morbidity and mortality and the cost to society of such a policy. The available scientific evidence does not support a recommendation for cesarean delivery for improving survival or decreasing morbidity for the extremely premature fetus.
\end{abstract}

Keywords: Extremely premature fetus; fetal growth restriction (FGR); gestational age; intracranial hemorrhage $(\mathrm{ICH})$.

\footnotetext{
${ }^{*}$ Corresponding author:

Daniel W. Skupski, MD

New York Hospital Queens

56-45 Main Street

Room M-365

Flushing

New York 11355

USA

Tel.: +1-718-670-1495

Fax: +1-718-539-1669

E-mail: dwskupsk@med.cornell.edu
}

\begin{abstract}
Introduction
A very important clinical question has been raised recently regarding the proper course of action when a woman presents with preterm labor at a extremely preterm gestational age with a cephalic presenting fetus. Should the cephalic-presenting, extremely preterm fetus be allowed a vaginal birth or be delivered by cesarean section? A combination of factors has provided the impetus to review this topic and develop this statement. These factors include a rising rate of cesarean delivery and recent scientific information purporting to show improved survival or decreased morbidity for the neonate when cesarean delivery is performed for extreme prematurity (Tables 1 and 2). This topic is very important for the health of women and infants worldwide.
\end{abstract}

\section{Evaluation of the scientific literature}

Table 1 shows the available quality studies examining the relationship of delivery mode and survival for cephalicpresenting preterm fetuses $[7,8,11-14,16,17,20,21]$. All of these studies are retrospective in nature, limiting the quality of the information available. There have been attempts to perform randomized trials, of which several have failed [4]. The highest quality scientific information is thus unavailable. Studies are included in each of the tables only if regression analysis, the scientific method that attempts to control for confounding variables that may produce positive results in univariate analyses, was performed. The simple fact that no "gold-standard" scientific evidence exists for this topic argues that further study is necessary before setting any standard. It is our opinion that any extreme intervention (i.e., a surgical procedure such as cesarean delivery) is unlikely to be justified for many reasons.

The results in Table 1 appear to be mixed. There are several studies that suggest that cesarean delivery is associated with improved survival of extremely preterm fetuses, while many others show no such association. The recent 2006 study, which far outweighs the others in numbers, shows mixed results for different gestational age or birth weight categories. Most of the fetuses in all of these studies were of significantly higher birth weights 
Table 1 Relevant quality studies on the effect of delivery mode on survival of severely preterm cephalic fetuses.*

\begin{tabular}{|c|c|c|c|c|}
\hline First author & Year & Number & Birth weight & Findings \\
\hline Wylie & 2008 & 2466 & $<1500 \mathrm{~g}$ & $\begin{array}{l}\text { Negative }^{a} \text { for all } \\
\text { Positive }^{b} \text { for FGR }\end{array}$ \\
\hline Lee & 2006 & 40,116 & $<1500 \mathrm{~g}$ & $\begin{array}{l}\text { Positive for all } \\
\text { Positive for FGR }\end{array}$ \\
\hline Muhuri & 2006 & 60,364 & $<1500 \mathrm{~g}$ & $\begin{array}{l}\text { Mixed results } \\
\text { Positive for } 500-749 \mathrm{~g} \\
\text { Negative for } 750-999 \mathrm{~g} \\
\text { Positive for } 1000-1249 \mathrm{~g} \\
\text { Harmful for } 1250-1499 \mathrm{~g}\end{array}$ \\
\hline Riskin & 2004 & 2955 & $<1500 \mathrm{~g}$ & Negative \\
\hline Jonas & 1999 & 5182 & $500-1500 \mathrm{~g}$ & $\begin{array}{l}\text { Positive for } 500-749 \mathrm{~g} \\
\text { Negative for } 750-999 \mathrm{~g} \\
\text { Negative for } 1000-1249 \mathrm{~g} \\
\text { Negative for } 1250-1499 \mathrm{~g} \\
\text { Harmful for } 750-1499 \mathrm{~g}\end{array}$ \\
\hline Jonas & 1997 & 2763 & $500-1500 \mathrm{~g}$ & Negative \\
\hline Malloy & 1991 & 1765 & $500-1500 \mathrm{~g}$ & Negative \\
\hline Malloy & 1989 & 3095 & $<1500 \mathrm{~g}$ & Negative \\
\hline Worthington & 1983 & 214 & $500-1500 \mathrm{~g}$ & Negative \\
\hline
\end{tabular}

Studies are listed in the reference section beginning with the most recent first.

${ }^{*}$ All studies are retrospective and all attempt to find independent predictors of outcomes by using regression analysis.

aNegative designates no independent effect of cesarean delivery on survival.

bPositive designates an independent effect where cesarean delivery is associated with an improved survival.

$\mathrm{FGR}=$ fetal growth restriction.

Table 2 Relevant quality studies on the effect of delivery mode on the occurrence of intracranial hemorrhage (ICH) in severely preterm fetuses.*

\begin{tabular}{|c|c|c|c|c|}
\hline First author & Year & Number & Birth weight & Findings \\
\hline Wylie & 2008 & 2466 & $<1500 \mathrm{~g}$ & Positive $^{a}$ for ICH-OR $0.73(0.55-0.97)$ \\
\hline Riskin & 2008 & 5033 & $<1500 \mathrm{~g}$ & Negative $^{b}$ for ICH-OR $0.98(0.77-1.24)$ \\
\hline Haque & 2008 & 213 & $<1250 \mathrm{~g}$ & Negative for ICH-VD $47.7 \%$ vs. CD $46.8 \%$ \\
\hline Ment & 1995 & 505 & $600-1250 \mathrm{~g}$ & Positive for ICH-RR 0.41 (0.34-0.49) \\
\hline Malloy & 1991 & 1765 & $500-1500 \mathrm{~g}$ & Positive for ICH-RR 0.71 (0.55-0.90) \\
\hline Worthington & 1983 & 214 & $500-1500 \mathrm{~g}$ & Negative for IVH-VD $23 \%$ vs. CD $15 \%$ \\
\hline
\end{tabular}

Studies are listed in the reference section beginning with the most recent first.

${ }^{*}$ All studies are retrospective except for one randomized trial (Ment) and all attempt to find independent predictors of outcomes by using regression analysis.

aPositive designates an independent effect where cesarean delivery is associated with a decreased occurrence of $\mathrm{ICH}$.

${ }^{b}$ Negative designates no independent effect of cesarean delivery on the occurrence of ICH.

than those of the extremely preterm gestational ages. This further limits the applicability of the results. These data do not provide enough scientific evidence to support a "blanket" recommendation for cesarean delivery as a method to improve survival for the severely preterm fetus.

An equally important issue is that of decreased morbidity. The most critical short-term morbidity for the extremely preterm fetus/neonate is intracranial hemorrhage $(\mathrm{ICH})$. Table 2 shows the available quality studies evaluating the relationship between delivery mode and $\mathrm{ICH}$ for cephalic-presenting fetuses [6, 14, 15, 18, 20, 21]. These results also appear to be mixed. There are several studies that suggest that cesarean delivery is associated with a decreased incidence of $\mathrm{ICH}$ in extremely preterm survivors, whereas many others do not. Even the two most recent and largest studies show mixed results. Most of the fetuses in these studies were of significantly higher birth weights than those of the extremely preterm gestational ages. This further limits the applicability of the results. These data do not provide enough scientific evidence to support a recommendation for cesarean delivery as a method to decrease the incidence of $\mathrm{ICH}$ in the extremely preterm fetus. The study by Ment et al. although randomized, did not directly examine the effect of delivery mode on $\mathrm{ICH}$, but examined instead the possible protective effect of indomethacin on the occurrence of $\mathrm{ICH}$. The study by Ment et al. does not provide "gold standard" evidence.

An important circumstance where cesarean delivery might be expected to be of benefit to the extremely preterm fetus is fetal growth restriction (FGR). The available 
information on this topic comes from only two recent retrospective studies. These two studies are included in Table $1[11,21]$. There are not enough data available to support a recommendation for cesarean delivery to improve survival for the extremely preterm fetus with FGR. Until further evidence is available, cesarean delivery in this circumstance should be limited to the occurrence of fetal heart rate abnormalities or other evidence of nonreassuring fetal status.

Although the scientific data show the possibility of a benefit of cesarean delivery on fetal and neonatal morbidity and mortality, it is likely that any possible effect, if present at all, is mild and not reliably reproduced. Until data from randomized trials are available [4] or further retrospective evidence accrues that demonstrates a benefit more clearly and consistently, a policy of cesarean delivery for the extremely premature fetus cannot be supported.

\section{The decision for delivery}

The difficulty in evaluating the scientific literature on this topic is compounded by some other issues. One of these is that a decision for cesarean delivery requires that obstetricians make a clinical decision that labor is active and that delivery is imminent. Unfortunately, it is not possible to reliably determine when a patient is truly in labor and delivery is imminent, due to the varying dynamics of preterm labor. Especially with tocolysis, patients can be $6 \mathrm{~cm}$ or more dilated - definitively meeting the criteria for "active labor" - and not deliver for days or even weeks. This means that retrospective studies that show that cesarean is of benefit are unable to consider the negative impact of the prospective decision to perform cesarean. Adding a week or more to the intrauterine life of the fetus may be of great benefit. An increase of gestational age at birth increases the chance for survival without handicap approximately by $3 \%$ per day in early gestation [2].

\section{Maternal morbidity and mortality}

Another issue is the impact of a policy to recommend cesarean delivery for the extremely premature fetus on the health of women worldwide, especially when it is predictable that they will want to have large families. Cesarean delivery, especially at an extremely preterm gestational age, increases the risk of morbidity and mortality to the woman and her future fetuses, and these risks increase with each additional cesarean [1, 3, 5, 9, $10,19]$. These risks are due to placenta previa/accreta, major obstetric hemorrhage, uterine rupture, fetal death, peripartum hysterectomy and maternal death during subsequent pregnancies.

\section{Cost}

Although speculative, it is probably true that a policy of recommending cesarean delivery for the very premature fetus would increase health care costs worldwide. This is another factor to consider in the evaluation of such a policy.

\section{Summary}

Although there are studies suggesting that delivery of the extremely premature infant by cesarean may be associated with a lower mortality and lower incidence of $\mathrm{ICH}$, the evidence is not strong and conclusive enough to recommend routine cesarean delivery in this population. In addition, the difficulty in determining when delivery is imminent and the possible detrimental effects on maternal and fetal health in future pregnancies strengthen the position that the routine cesarean delivery cannot be recommended in this population.

\section{References}

[1] ACOG Committee on Obstetric Practice. ACOG Committee Opinion, Number 266, January 2002: placenta accreta. Obstet Gynecol. 2002;99:169-70.

[2] Ancel PY, Livinec F, Larroque B, Marret S, Arnaud C, Pierrat $\mathrm{V}$, et al. Cerebral palsy among very preterm children in relation to gestational age and neonatal ultrasound abnormalities: the epipage cohort study. Pediatrics. 2006;117: 828-35.

[3] Clark SL, Koonings PP, Phelan JP. Placenta previa/accreta and prior cesarean section. Obstet Gynecol. 1985;66:8992.

[4] Grant A, Glazener CMA. Elective caesarean section versus expectant management for delivery of the small baby. Cochrane Database of Systematic Reviews 2001, Issue 2: Art. No.: CD000078. DOI: 10.1002/14651858.CD000078.

[5] Grobman WA, Gersnoviez R, Landon MB, Spong CY, Leveno KJ, Rouse DJ, for the NICHD MFMU Network. Pregnancy outcomes for women with placenta previa in relation to the number of prior cesarean deliveries. Obstet Gynecol. 2007;110:1249-55.

[6] Haque KN, Hayes AM, Ahmed Z, Wilde R, Fong CY. Caesarean or vaginal delivery for preterm very low birth weight $(\leq 1,250 \mathrm{~g})$ infant: experience from a district general hospital in UK. Arch Gynecol Obstet. 2008;277:207-12.

[7] Jonas HA, Lumley JM. The effect of delivery mode on neonatal mortality in very low birthweight infants born in Victoria, Australia: cesarean section is associated with increased survival in breech-presenting, but not vertexpresenting, infants. Paedatric Perinatal Epidemiol. 1997; 11:181-99.

[8] Jonas HA, Khalid N, Schwartz SM. The relationship between caesarean section and neonatal mortality in very low birthweight infants born in Washington State, USA. Paediatric Perinatal Epidemiol. 1999;13:170-89.

[9] Kastner ES, Figueroa R, Garry D, Maulik D. Emergency 
peripartum hysterectomy: experience at a community teaching hospital. Obstet Gynecol. 2002;99:971-5.

[10] Kwee A, Bots ML, Visser GH, Bruinse HW. Emergency peripartum hysterectomy: a prospective study in The Netherlands. Eur J Obstet Gynecol Reprod Biol. 2006;124: 187-92. Epub 2005 Jul 18.

[11] Lee HC, Gould J. Survival advantage associated with cesarean delivery in very low birth weight vertex neonates. Obstet Gynecol. 2006;107:97-105.

[12] Lee HC, Gould J. Survival advantage associated with cesarean delivery in very low birth weight vertex neonates (letter). Obstet Gynecol. 2007;109:1203.

[13] Malloy MH, Rhoads GG, Schramm W, Land G. Increasing cesarean section rates in very low-birth weight infants. Effect on outcome. J Am Med Assoc. 1989;262:1475-8.

[14] Malloy MH, Onstad L, Wright E, for the NICHD Neonatal Research Network. The effect of cesarean delivery on birth outcome in very low birth weight infants. Obstet Gynecol. 1991;77:498-503.

[15] Ment LR, Oh W, Ehrenkranz RA, Philip AG, Duncan CC, Makuch RW. Antenatal steroids, delivery mode, and intraventricular hemorrhage in preterm infants. Am J Obstet Gynecol. 1995;172:795-800.

[16] Muhuri PK, MacDorman MF, Menacker F. Method of delivery and neonatal mortality among very low birth weight infants in the United States. Maternal and Child Health J. 2006;10:47-53.

[17] Riskin A, Riskin-Mashiah S, Lusky A, Reichman B. The relationship between delivery mode and mortality in very low birthweight singleton vertex-presenting infants. $\mathrm{Br} \mathrm{J}$ Obstet Gynaecol. 2004;111:1365-71.

[18] Riskin A, Riskin-Mashiah S, Bader D, Kugelman A, LernerGeva L, Boyko V, et al. Delivery mode and severe intraventricular hemorrhage in single, very low birth weight, vertex infants. Obstet Gynecol. 2008;112:21-8.

[19] Silver RM, for the MFMU Metwork of the NICHD. The MFMU cesarean section registry: maternal morbidity associated with multiple repeat cesarean delivery. Abstract. Am J Obstet Gynecol. 2004:191:S17.

[20] Worthington D, Davis LE, Grausz JP, Sobocinski K. Factors influencing survival and morbidity with very low birth weight delivery. Obstet Gynecol. 1983;62:550-5.

[21] Wylie BJ, Davidson LL, Batra M, Reed SD. Method of delivery and neonatal outcome in very low birthweight vertex-presenting fetuses. Am J Obstet Gynecol. 2008; 198:640.e1-7.

The authors stated that there are no conflicts of interest regarding the publication of this article.

Previously published online August 17, 2009. 